\title{
Ecobrick Sebagai Solusi Dinding Nonstruktural Ramah Lingkungan
}

\author{
(Ecobrick As an Eco-friendly Nonstructural Wall Solution)
}

\author{
Fazrina Andriani Sakinah Lubis ${ }^{1^{*}}$ dan Erizal $^{1}$ \\ ${ }^{1}$ Departemen Teknik Sipil dan Lingkungan, Fakultas Teknologi Pertanian, Institut Pertanian Bogor. \\ J1. Raya Dramaga, Kampus IPB Dramaga, PO BOX 220, Bogor, Jawa Barat, Indonesia \\ *Penulis korespondensi: Fazrina_98@apps.ipb.ac.id
}

Diterima: 8 April 2021

Disetujui: 20 Juli 2021

\begin{abstract}
Population growth increased in the need for dwelling which impacted to high demand for bricks. However, bricks have a negative impact on the environment due to the materials and the production prosses. Population growth also effected an increase amount of plastic waste that has a risk to the health and environment. This research aimed to analyze the compressive and flexural strength of brick and ecobrick (PET bottle filled with plastic waste) wall, to know degree of difference in strength between both wall, and to compare the cost of making the wall. This research was started from preparation, manufactured, cured, and tested the specimens. The cost analysis refers to the Bogor district in 2019. The result was obtained compressive strength of brick is higher than ecobrick, which is brick 2,38 MPa and ecobrick 1,31 MPa. Flexural strength of ecobrick is higher than brick, which is ecobrick 1,23 MPa and brick 1,18 MPa. T-test show that compressive strength both wall is significantly different, while the flexural strength both wall is not significantly different. The cost of making ecobrick walls is $20 \%$ cheaper than brick walls.
\end{abstract}

Keywords: Brick, Nonstructural Wall, Ecobrick, Flexural Strength, Compressive Strength.

\section{PENDAHULUAN}

Seiring berjalannya waktu, jumlah penduduk Indonesia semakin meningkat. Berdasarkan data proyeksi penduduk Indonesia tahun 2010-2035, laju pertumbuhan penduduk Indonesia tahun 2015-2020 sebesar 1,19 persen pertahun (BPS 2013). Pertambahan penduduk mengakibatkan berkurangnya sumber daya alam dan peningkatan jumlah sampah (Shoubi et al. 2013). Berkurangnya sumber daya alam salah satunya disebabkan oleh tingginya permintaan tempat tinggal. Jumlah tempat tinggal yang terus meningkat mengakibatkan kenaikan permintaan terhadap bahan bangunan salah satunya batu bata yang digunakan sebagai dinding atau pemisah ruangan.
Batu bata banyak digunakan masyarakat karena batu bata memiliki keunggulan yaitu murah, kuat, dan tahan api. Namun, penggunaan batu bata memiliki dampak negatif terhadap lingkungan karena bahan baku batu bata yang terbuat dari tanah subur produktif, sehingga pembuatan batu bata menyebabkan berkurangnya lahan pertanian. Berdasarkan penelitian (Nursia \& Hurudu, 2016), produksi batu bata mengakibatkan lahan di sekitar daerah pembuatan batu bata mengalami kekeringan, hilangnya lapisan tanah yang subur, dan menurunnya kapasitas infiltrasi tanah yang dalam jangka panjang dapat berdampak pada terjadinya longsor. Selain itu proses pembakaran dalam pembuatan batu bata yang menggunakan suhu tinggi 
mengakibatkan penurunan kualitas udara (Supriyadi \& Septinar, 2018).

Kenaikan jumlah penduduk juga berakibat terhadap jumlah sampah yang dihasilkan. Jenis sampah yang sering ditemui disekitar lingkungan ialah plastik. Plastik banyak digunakan masyarakat karena murah, ringan, tidak mudah pecah, dan mudah dibentuk. Menurut data Kementerian Lingkungan Hidup dan Kehutanan (KLHK) menyebutkan bahwa total jumlah sampah di Indonesia pada tahun 2016 mencapai 66 juta ton, dimana jumlah sampah plastik diperkirakan mencapai 10,56 juta ton atau $16 \%$ dari total sampah. Plastik dapat bertahan hingga ratusan tahun, namun penggunaan plastik yang tidak sesuai peryaratan dapat berisiko pada kesehatan manusia seperti kanker, alergi, dan keracunan karena bahan kimia yang terkandung di dalam plastik. Berdasarkan data Statistik Lingkungan Hidup Indonesia tahun 2018 bahwa hanya sebesar $1,2 \%$ plastik yang digunakan kembali, 66,8\% dibakar, dan sisanya berakhir di tempat pembuangan sampah, saluran air, dan dipinggir jalan yang menyebabkan pencemaran lingkungan (BPS 2018).

Seiring berkembangnya ilmu pengetahuan dan teknologi konstruksi, banyak inovasi baru terkait subsitusi batu bata agar didapatkan pengganti batu bata yang lebih ramah lingkungan dan ekonomis. Batu Bata merupakan bahan bangunan yang difungsikan sebagai komponen dinding nonstruktural yang tidak menanggung beban secara langsung. Oleh karena itu, penggunaan ecobrick dimksudkan untuk pengganti bata sebagai pengisi dinding nonstruktural. Ecobrick ialah botol PET yang diisi dengan material plastik. Subsitusi bata dengan ecobrick ditujukan untuk mengurangi dampak negatif yang ditimbulkan dari pembuatan bata serta memanfaatkan sampah plastik yang mencemari lingkungan.

Tujuan penelitian ini ialah sebagai berikut :

1. Menganalisis kualitas dinding ecobrick berdasarkan nilai kuat tekan dan lentur dibandingkan dengan dinding bata.

2. Mengetahui tingkat perbedaan kekuatan bata merah dan ecobrick signifikan atau tidak.

3. Menganalisis perbandingan biaya pekerjaan pembuatan dinding ecobrick dan bata.

\section{METODOLOGI}

Penelitian ini dilakukan dengan menggunakan data primer yang diperoleh dari pengujian dan perhitungan terhadap benda uji. Alat dan bahan yang digunakan pada penelitian ini ialah botol PET ukuran 1,5 liter, sampah plastik, bata merah, semen portland, pasir, stik kayu/bambu, benang nilon, ayakan pasir, sendok semen, meteran, gergaji, martil, cetakan atau bekisting yang terbuat dari multiplek, ember, alat tulis, timbangan, wadah pengadukan mortar, dan gunting. Pengujian kuat tekan dan kuat lentur benda uji menggunakan alat universal testing machine (UTM). Penelitian ini terdiri dari beberapa tahapan yaitu studi pustaka, persiapan, pembuatan, perawatan, pengukuran, dan pengujian benda uji. Data primer yang dikumpulkan berupa data uji tekan dan uji lentur pasangan dinding. Selain itu, dilakukan analisis perbandingan biaya antara penggunaan batu bata dan ecobrick.

\section{Pembuatan Benda Uji}

Benda uji yang dibuat berupa dinding dari pasangan bata dan ecobrick. Dimensi dinding bata yang dibuat yaitu 
tinggi $25 \mathrm{~cm}$, panjang $36 \mathrm{~cm}$, dan lebar $12 \mathrm{~cm}$ dan dinding ecobrick dengan tinggi $25 \mathrm{~cm}$, panjang $36 \mathrm{~cm}$ dan lebar 10 $\mathrm{cm}$. Jumlah benda uji yang dibuat yaitu tiga buah untuk setiap variabel pengujian (kuat tekan dan kuat lentur), sehingga total benda uji untuk satu jenis dinding berjumlah enam. Benda uji dinding merupakan modifikasi dari penelitian Pascanawaty et al. (2016) dan Leksono \& Kristijanto. (2012). Benda uji dan penyusunannya dapat dilihat pada Gambar 1.

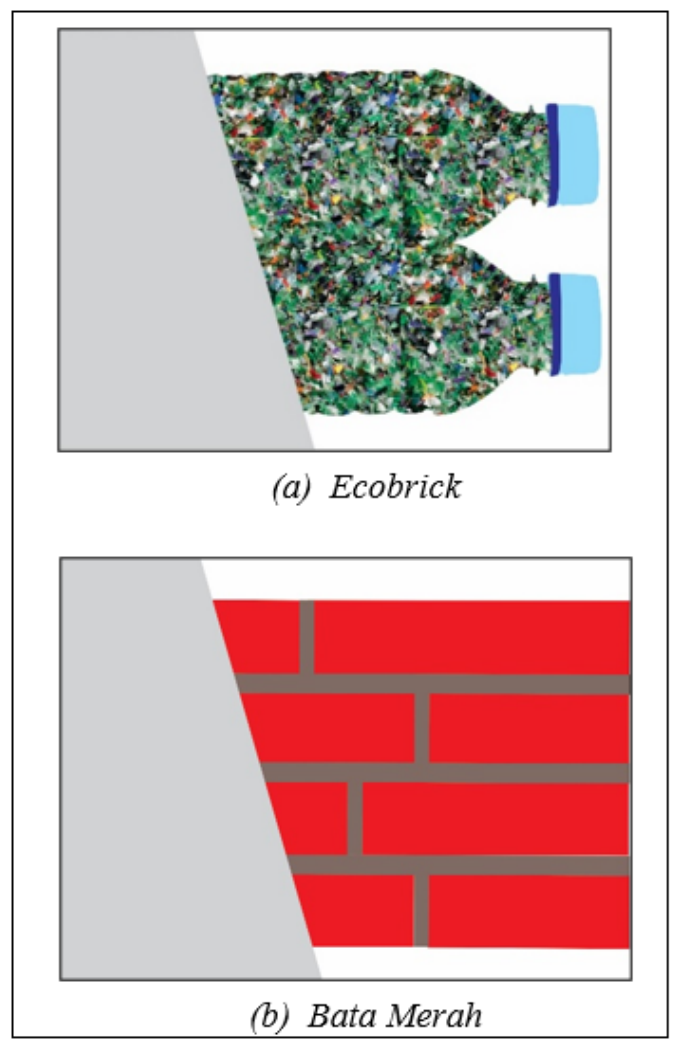

Gambar 1 Benda Uji yang Dimodifikasi

\section{Pengujian Benda Uji}

Pengujian dilakukan setelah benda uji berumur 28 hari. Pengujian yang dilakukan ialah uji kuat tekan dan kuat lentur dengan menggunakan alat universal testing machine (UTM). Data pengujian benda uji yang diperoleh digunakan dalam menganalisis dan membandingkan kedua jenis benda uji yaitu dinding bata dan dinding ecobrick.

\section{Uji Kuat Tekan}

Pengujian ini dimaksudkan untuk mendapatkan nilai kuat tekan (compressive strength) dinding dengan benda uji dinding. Pengujian ini dilakukan hingga benda uji hancur oleh mesin tekan. Pemodelan uji kuat tekan pada Gambar 3 yang mengacu pada SNI 03-4164-1996 (BSN 1996a) serta BS EN 772-1-2011, dimana benda uji dibebani beban merata sampai hancur.

$\mathrm{Fc}^{\prime}=\frac{\mathrm{Fmax}}{\mathrm{A}}$

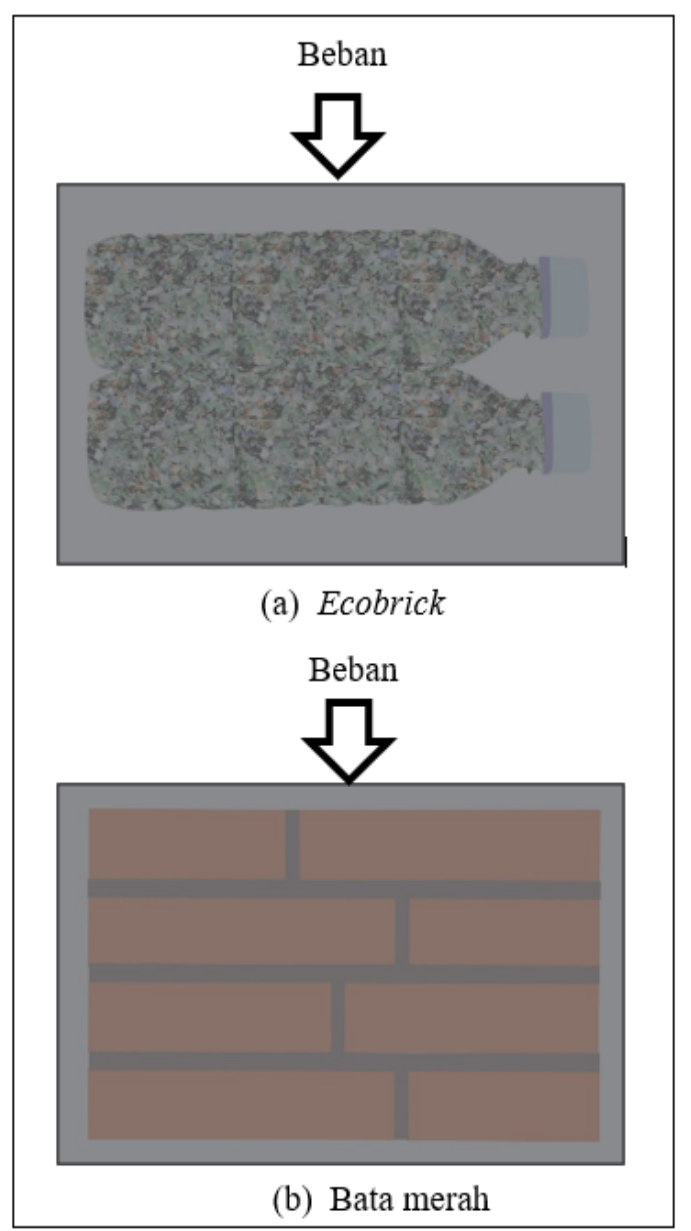

Gambar 2 Posisi Pembebanan Kuat Tekan pada Benda Uji 


\section{Uji Kuat Lentur}

Kuat lentur dinding adalah kemampuan balok dinding yang diletakkan arah tegak lurus sumbu benda uji yang diberikan pada dinding. Pengujian kuat lentur dimaksudkan untuk mengetahui besarnya nilai kuat lentur maksimum sampai benda uji patah. Pemodelan uji kuat lentur pada Gambar 3.

$\mathrm{Flt}=\frac{3 \mathrm{PL}}{2 \mathrm{bh}^{2}}$

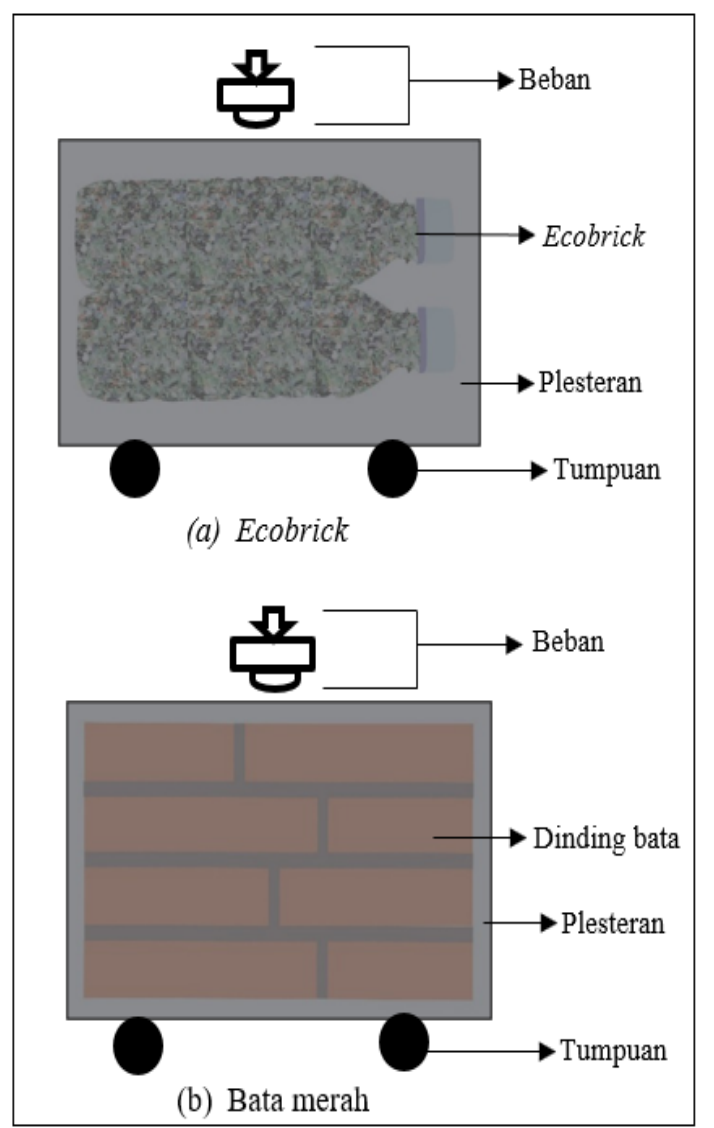

Gambar 3 Posisi Pembebanan Kuat Lentur pada Benda Uji

Keterangan:

Fc' : Kuat tekan dinding (MPa)

Fmax : Beban maksimum (N)

A : Luas permu'kaan benda uji

Flt : Kuat lentur dinding (MPa)

$\mathrm{L} \quad$ : panjang bentang $(\mathrm{mm})$

$\mathrm{P} \quad$ : Beban maksimum $(\mathrm{N})$

b : Lebar benda uji (mm) $\mathrm{h}$ : Tinggi penampang patah
$(\mathrm{mm})$

\section{Analisis Data}

Data yang didapatkan dicatat dan diolah menggunakan metode statistika uji T. Uji Tdilakukan untuk penarikan kesimpulan pengujian dalam penelitian. Uji $\mathrm{T}$ pada penelitian dilakukan secara manual.

\section{Analisis Perbandingan Biaya Pekerjaan Dinding Ecobrick dan Pasangan Bata}

Penelitian ini juga membahas perbandingan biaya pembuatan dinding ecobrick dan pasangan bata dengan luasan $1 \mathrm{~m}^{2}$. Analisis biaya pembuatan dinding mengacu pada SNI 2837-2008 (BSN 2000a) tentang "Tata Cara perhitungan Harga Satuan Pekerjaan Plesteran untuk Konstruksi Gedung dan Perumahan" dan SNI 6897-2008 (BSN 2008b) tentang "Tata Cara Perhitungan Harga Satuan Pekerjaan Dinding untuk Konstruksi Gedung dan perumahan". Harga satuan material yang digunakan sesuai dengan harga bahan dilapangan, sedangkan upah tenaga kerja yang digunakan disesuaikan dengan harga satuan upah pekerja di Kabupaten Bogor Tahun 2019 (KEPGUB 2019).

\section{HASIL DAN PEMBAHASAN}

Tabel 1 Nilai Kuat Tekan Dinding Bata

\begin{tabular}{cccc}
\hline \multirow{2}{*}{ No } & Luas (A) & $\begin{array}{c}\text { Beban } \\
\text { Maksimum } \\
(\text { Fmax })\end{array}$ & $\begin{array}{c}\text { Kuat Tekan } \\
\left(\mathrm{Fc}^{\prime}\right)\end{array}$ \\
\cline { 2 - 4 } & & $\mathrm{KN}$ & $\mathrm{N} / \mathrm{mm}^{2}$ \\
\cline { 2 - 4 } $\mathrm{cm}^{2}$ & 49,41 & 2,06 \\
2 & 240 & 53,90 & 2,45 \\
3 & 220 & 56,15 & 2,34 \\
\hline & 240 & 53,16 & 2,28 \\
\hline
\end{tabular}


Tabel 2 Nilai Kuat Tekan Dinding Ecobrick

\begin{tabular}{|c|c|c|c|}
\hline \multirow[t]{2}{*}{ No } & $\begin{array}{l}\text { Luas } \\
\text { (A) }\end{array}$ & $\begin{array}{l}\text { Beban Maksimum } \\
\text { (Fmax) }\end{array}$ & $\begin{array}{c}\text { Kuat } \\
\text { Tekan } \\
\text { (Fc') }\end{array}$ \\
\hline & $\mathrm{cm}^{2}$ & $\mathrm{KN}$ & $\mathrm{N} / \mathrm{mm}^{2}$ \\
\hline 1 & 200 & 25,83 & 1,30 \\
\hline 2 & 200 & 26,95 & 1,35 \\
\hline 3 & 200 & 26,50 & 1,32 \\
\hline & a-Rata & 26,43 & 1,31 \\
\hline
\end{tabular}

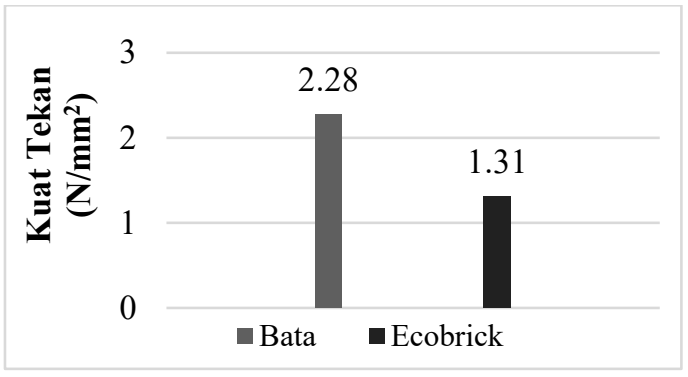

Gambar 4 Perbandingan Nilai Kuat Tekan Dinding

Berdasarkan hasil yang diperoleh, kekuatan tekan yang dihasilkan dinding bata lebih besar dibandingkan kuat tekan ecobrick. Hal ini dikarenakan ecobrick terbuat dari plastik PET yang tebalnya hanya $5 \mathrm{~mm}$ dan isian plastik yang cukup ringan sehingga mempengaruhi kuat tekan yang dihasilkan, serta dapat diakibatkan karena lemahnya ikatan antara plastik dan mortar, ikatan yang buruk berakibat pada menurunnya kuat tekan yang dihasilkan dinding.

Tabel 3 Nilai Kuat Lentur Dinding Pasangan Bata

\begin{tabular}{lcc}
\hline \multirow{2}{*}{ No } & Beban Maksimum (P) & $\begin{array}{c}\text { Kuat } \\
\text { Lentur } \\
\text { (Flt) }\end{array}$ \\
\cline { 2 - 3 } & $\mathrm{KN}$ & $\mathrm{N} / \mathrm{mm}^{2}$ \\
\hline 1 & 35,26 & 1,23 \\
2 & 36,83 & 1,23 \\
3 & 30,32 & 1,09 \\
\hline Rata-Rata & 34,14 & 1,18 \\
\hline
\end{tabular}

Tabel 4 Nilai Kuat Lentur Dinding Ecobrick

\begin{tabular}{lcc}
\hline \multirow{2}{*}{ No } & Beban Maksimum (P) & $\begin{array}{c}\text { Kuat Lentur } \\
(\text { Flt })\end{array}$ \\
\cline { 2 - 3 } & & $\mathrm{NN}$ \\
\hline 1 & 28,32 & 1,22 \\
2 & 28,07 & 1,21 \\
3 & 29,20 & 1,26 \\
\hline Rata-Rata & 28,52 & 1,23 \\
\hline
\end{tabular}

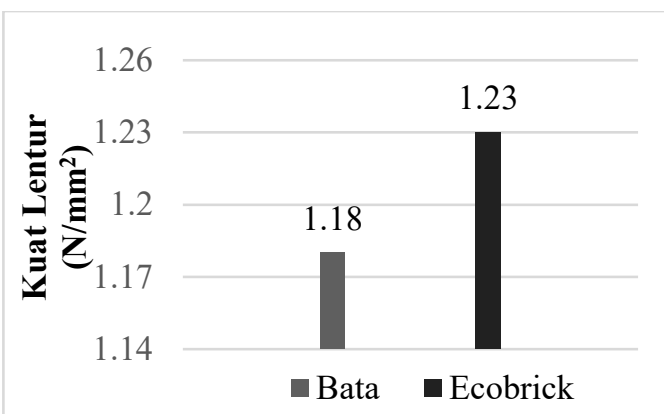

Gambar 5 Perbandingan Nilai Kuat Lentur Dinding

Berdasarkan hasil pengujian dinding pasangan bata dan ecobrick nilai kuat lentur dinding ecobrick lebih besar dibandingkan dengan bata, peningkatan kuat lentur dinding ecobrick sebesar $4,2 \%$ dibandingkan bata. Hal ini dikarenakan bata terbuat dari tanah lempung yang dibakar sehingga bata lebih kaku dan keras oleh karena itu kekuatan lentur bata kecil, sedangkan ecobrick terbuat dari plastik PET yang bersifat elastis sehingga mengakibatkan nilai kuat lentur ecobrick lebih tinggi dibandingkan bata. Nilai kuat lentur yang tinggi mengakibatkan dinding semakin kuat ketahanannya terhadap beban gempa. 
Tabel 5 Hasil Uji T terhadap Dua Variabel Pengujian

\begin{tabular}{ccccc}
\hline No & Variabel & $\begin{array}{c}\mathrm{T} \\
\text { hitung }\end{array}$ & $\begin{array}{c}\mathrm{T} \\
\text { tabel }\end{array}$ & Keterangan \\
\hline 1 & $\begin{array}{c}\text { Kuat } \\
\text { tekan }\end{array}$ & 8,25 & 2,13 & $\begin{array}{c}\text { Perbedaan } \\
\text { signifikan } \\
\text { Tidak ada } \\
\text { perbedaan } \\
\text { yang } \\
\text { signifikan }\end{array}$ \\
\hline
\end{tabular}

Setelah dilakukan pengujian kuat tekan dan kuat lentur dinding bata dan ecobrick, selanjutnya dilakukan analisis statistik uji t, hal ini dilakukan untuk membedakan pengaruh penggunaan dinding ecobrick terhadap dinding bata. Analisis uji $t$ dilakukan dengan perhitungan secara manual. Berdasarkan perhitungan terhadap kuat tekan didapatkan nilai thitung sebesar 8,25. Mengacu pada teori uji $t$ apabila nilai thitung lebih kecil dari t tabel maka $\mathrm{H} 0$ ditolak dan $\mathrm{Ha}$ diterima berarti ada perbedaan antara kedua sampel (terdapat perbedaan penggunaan bata dan ecobrick terhadap kuat tekan). Hasil uji kuat lentur didapatkan nilai thitung sebesar 0,32. Mengacu pada teori uji $t$ bahwa apabila nilai thitung lebih besar dari ttabel maka H0 diterima dan $\mathrm{Ha}$ ditolak berarti tidak ada perbedaan yang signifikan antara kedua sampel (tidak ada perbedaan penggunaan dinding bata dan ecobrick terhadap kuat lentur).

\section{Analisis Harga Satuan Material dan Pekerja}

\section{Perhitungan Biaya Pekerjaan Dinding Bata dan Ecobrick}

Berikut merupakan perhitungan biaya pengerjaan dinding bata dengan plesteran dan dinding ecobrick, dinding bata yang dibuat untuk tebal $1 / 2$ bata, analisis biaya pembuatan dinding mengacu pada SNI 2837-2008 (BSN 2008a) dan SNI 6897-2008 (BSN 2008b). Uraian perhitungan biaya pembuatan dinding bata dengan plesteran dan dinding ecobrick sebagai berikut:

\section{Perhitungan Dinding Bata}

1. Ukuran bata yang digunakan $20 \mathrm{~cm} \mathrm{x}$ $10 \mathrm{~cm} \times 5 \mathrm{~cm}$ sehingga dalam $1 \mathrm{~m}^{2}$ dibutuhkan 80 buah bata merah dengan spesi $1 \mathrm{~cm}$. Perhitungannya sebagai berikut:

$$
\frac{10000 \mathrm{~cm}^{2}}{(20+1) *(5+1)}=79,37 \approx 80 \text { buah }
$$

2. Jumlah bata merah yang dibutuhkan sebesar 79,37 buah yang dibulatkan sebanyak 80 buah, harga per bata yaitu Rp 800 sehingga untuk membuat $1 \mathrm{~m}^{2}$ bata dibutuhkan biaya sebesar : 80 x Rp $800=\operatorname{Rp} 64.000$.

3. Volume spesi yang dbutuhkan dapat dihitung dengan menghitung volume dinding pasangan bata dikurangi volume total bata.

\begin{tabular}{lll} 
Vdinding bata & $100 \times 100 \times 10$ & $=100.000 \mathrm{~cm}^{3}$ \\
Vbata total & $(20 \times 10 \times 5) \times 80 \mathrm{buah}$ & $=80.000 \mathrm{~cm}^{3}-$ \\
\hline Vspesi & $=20.000 \mathrm{~cm}^{3}$ & $=0.02 \mathrm{~m}^{3}$
\end{tabular}

4. Harga pasir ialah $\mathrm{Rp} 350.000,-$ per $\mathrm{m}^{3}$ dan harga semen ialah Rp 55.000 per zak, harga semen harus diubah dahulu ke dalam $\mathrm{m}^{3}$ karena perhitungan menggunakan satuan $\mathrm{m}^{3}$, sehingga harus dihitung volume semennya, perhitungan volume semen sebagai berikut:

Volume semen $=\frac{50 \mathrm{Kg}}{3150 \frac{\mathrm{kg}}{\mathrm{m} 3}}=0,0159 \mathrm{~m}^{3}$

Satu zak semen dengan berat $50 \mathrm{~kg}$ dengan masa jenis semen 3.150 $\mathrm{kg} / \mathrm{m}^{3}$, dari data tersebut didapatkan volumenya sebesar $0,0159 \mathrm{~m}^{3}$, maka harga untuk $1 \mathrm{~m}^{3}$ semen sebesar $\mathrm{Rp}$ 3.465.000.

5. Spesi yang digunakan memiliki perbandingan Pasir dan semen 1:5, sehingga volume pasir dan semen 
yang digunakan dalam membuat campuran spesi ialah sebagai berikut: Pasir : $5 / 6 \times 0,02 \mathrm{~m}^{3}=0,017 \mathrm{~m}^{3}$

Semen : $1 / 6 \times 0,02 \mathrm{~m}^{3}=0,003 \mathrm{~m}^{3}$

Maka biaya dalam membuat campuran spesi ialah:

Pasir: $0,017 \mathrm{~m}^{3} \times \mathrm{Rp} 350.000=$

Rp 5.883

Semen: $0,003 \mathrm{~m}^{3} \times \mathrm{Rp} 3.465 .000=$ $\mathrm{Rp} 11.550$.

6. Setelah perhitungan biaya material dinding selesai, selanjutnya dihitung upah tenaga kerja yang diperlukan dalam mengerjakan dinding per $1 \mathrm{~m}^{2}$, perhitungannya sebagai berikut:

$\begin{array}{llllll}\text { Pekerja } & 0,3 & \text { OH } & \text { Rp 131.603 } & =\text { Rp 39.480 } \\ \text { Tukang Batu } & 0,1 & \text { OH } & \text { Rp 164.503 } & =\text { Rp } 16.40 \\ \text { KepalaTukang } & 0,01 & \text { OH } & \text { Rp 197.404 } & =\text { Rp } 1.974 \\ \text { Mandor } & 0,015 & \text { OH } & \text { Rp 230.305 } & =\text { Rp } 3.454\end{array}$

Setelah dihitung biaya material dan upah tenaga kerja didapatkan total biaya yang dikeluarkan dalam membuat $1 \mathrm{~m}^{2}$ dinding bata yaitu sebesar $\operatorname{Rp} 142.743 \approx \operatorname{Rp} \mathbf{1 4 2 . 8 0 0}$.

\section{Perhitungan Biaya Plesteran Bata}

1. Sebelum menentukan harga pembuatan plesteran perlu dihitung terlebih dahulu volume plesteran yang dibutuhkan untuk ketebalan 1 $\mathrm{cm}$, Perhitungannya sebagai berikut:

Vdinding + plesteran : $100 \times 100 \times 12=120.000 \mathrm{~cm}^{3}$

$\begin{array}{ll}\text { Vdinding bata : } 100 \times 100 \times 10 & =100.000 \mathrm{~cm}^{3}-\end{array}$

Perbandingan campuran plesteran antara semen dan pasir ialah 1:5, harga satuan pasir $\mathrm{Rp} 350.000$ serta semen sebesar Rp 3.465.000 per $\mathrm{m}^{3}$, perhitungan harga semen sama seperti perhtungan dinding bata, maka setelah didapatkan volume plesteran yang dibutuhkan, biaya kebutuhan material dapat dihitung sebagai berikut:

Pasir $=5 / 6 \times 0,02 \mathrm{~m}^{3}=0,017 \mathrm{~m}^{3}$ Semen $=1 / 6 \times 0,02 \mathrm{~m}^{3}=0,003 \mathrm{~m}^{3}$
Sehingga didapatkan biaya pasir dan semen yang dibutuhkan dalam 1 $\mathrm{m}^{2}$ sebesar:

Pasir $=0,017 \mathrm{~m}^{3} \times \mathrm{Rp} \quad 350.000=$ Rp 5.883

Semen $=0,003 \mathrm{~m}^{3} \times \mathrm{Rp} 3.465 .000=$ Rp 11.550

Setelah dilakukan perhitungan biaya material yang dibutuhkan selanjutnya dihitung upah tenaga kerja yang dibutuhkan, perhitungannya sebagai berikut:

\begin{tabular}{|c|c|c|c|c|}
\hline Pekerja & 0,2 & $\mathrm{OH}$ & Rp 131.603 & $=\operatorname{Rp} 26.320$ \\
\hline Tukang Batu & 0,1 & $\mathrm{OH}$ & Rp 164.503 & $=\operatorname{Rp} 16.450$ \\
\hline KepalaTukang & 0,01 & $\mathrm{OH}$ & Rp 197.404 & $=\mathrm{Rp} \quad 1.974$ \\
\hline Mandor & 0,01 & $\mathrm{OH}$ & $\operatorname{Rp} 230.305$ & $=R p$ \\
\hline
\end{tabular}

Maka total pembuatan biaya material dan upah pekerja pekerjaan plesteran ialah $\mathrm{Rp} 64.431 \approx \mathrm{Rp}$ 64.500. Sehingga, total harga pembuatan dinding pasangan bata dan plesteran sebesar Rp $207.174 \approx \mathbf{R p}$ 207.200.

\section{Biaya Pembuatan Ecobrick}

1. Botol plastik yang digunakan berukuran 1,5 liter yang memiliki diameter $8 \mathrm{~cm}$ dan panjang $34 \mathrm{~cm}$, sehingga dalam $1 \mathrm{~m}^{2}$ terdapat 36 buah botol plastik tanpa spesi yang diperhitungkan sebagai berikut: $\frac{(100 \mathrm{~cm}(100 \mathrm{~cm}-2 \mathrm{~cm})}{(8 \mathrm{~cm}+0.2 \mathrm{~cm}) * 34}=35,05 \approx 36$ buah

Besaran $0.2 \mathrm{~cm}$ merupakan diameter dari benang nilon yang digunakan dalam mengikat botol plastik, tebal spesi atas bawah yang digunakan dalam dinding botol ecobrick yaitu $1 \mathrm{~cm}$.

2. Pembuatan ecobrick dengan material yang dibeli dari pengepul, per $\mathrm{Kg}$ botol plastik dihargai $\mathrm{Rp} 5.000$, berat 1 botol plastik ialah 35 gram, sehingga $1 \mathrm{~kg}$ botol berjumlah 28 buah, sehingga harga satuan botol Rp 180. Kemasan pengisi ecobrick dihargai $\mathrm{Rp} 0$ karena merupakan 
plastik yang tidak laku di pengepul, Sehingga jumlah biaya yang dibutuhkan dalam membeli botol ecobrick untuk mengisi luasan $1 \mathrm{~m}^{2}$ ialah: 36 buah ecobrick $\times \mathrm{Rp} 180=\mathrm{Rp}$ 6.480 .

3. Ecobrick diikat satu sama lain menggunakan benang nilon, 1 Rol nilon sebesar Rp 10.000 yang cukup untuk mengikat ecobrick dalam $1 \mathrm{~m}^{2}$.

4. Pemasangan ecobrick menggunakan kawat ayam yang agar ecobrick tetap terjaga vertikalitasnya, harga kawat ayam yang diperlukan ialah $\mathrm{Rp}$ 15.000 per $\mathrm{m}^{2}$, dalam pemasangannya dibutuhkan kawat ayam pada bagian depan dan belakang bagian dinding sehingga dibutuhkan: $2 \times \operatorname{Rp} 15.000=$ Rp 30.000.

5. Kemudian, dalam memasang kawat ayam dibutuhkan paku, pembelian paku Rp 2000 cukup untuk memasang kawat ayam dalam $1 \mathrm{~m}^{2}$.

6. Setelah selesai perhitungan biaya material yang digunakan kemudian dilanjutkan dengan perhitungan upah pekerjaan dinding, sebagai berikut:

$\begin{array}{llllll}\text { Pekerja } & 0,18 & \mathrm{OH} & \mathrm{Rp} \mathrm{131.603} & =\mathrm{Rp} 24.191 \\ \text { Tukang Batu } & 0,09 & \mathrm{OH} & \mathrm{Rp} \mathrm{164.503} & =\mathrm{Rp} 15.119 \\ \text { KepalaTukang } & 0,009 & \mathrm{OH} & \mathrm{Rp} \mathrm{197.404} & =\mathrm{Rp} & 1.814 \\ \text { Mandor } & 0,009 & \mathrm{OH} & \mathrm{Rp} \mathrm{230.305} & =\mathrm{Rp} & 2.116\end{array}$

Sehingga total biaya pembuatan ecobrick ialah Rp 91.772.

\section{Perhitungan Biaya Plesteran Ecobrick}

1. Sebelum perhitungan biaya plesteran perlu dihitung dahulu volume plesteran yang akan digunakan. Tebal plesteran yang digunakan ialah $1 \mathrm{~cm}^{2}$, Perhitungan volume plesteran sebagai berikut:

\begin{tabular}{|c|c|}
\hline Vdinding + plesteran : $100 \times 100 \times 10$ & $=100.000 \mathrm{~cm}^{3}$ \\
\hline Vdinding : $\left(1 / 4 \times 3,14 \times(8,2)^{2} \times 34\right) \times 36$ & $=64.606 \mathrm{~cm}^{3}$ \\
\hline
\end{tabular}

Harga satuan pasir Rp 350.000 per $\mathrm{m}^{3}$ dan semen $\mathrm{Rp} 3.465 .000$ per $\mathrm{m}^{3}$, perhitungan harga semen sesuai dengan perhitungan pada dinding bata, sehingga untuk menghitung biaya dari pembuatan plesteran ecobrick dengan perbandingan semen dan pasir 1:5 sebagai berikut:

Pasir $=5 / 6 \times 0,035 \mathrm{~m}^{3}=0,029 \mathrm{~m}^{3}$

Semen $=1 / 6 \times 0,02 \mathrm{~m}^{3}=0,005 \mathrm{~m}^{3}$

Sehingga didapatkan plesteran sebagai berikut:

Pasir $=0,029 \mathrm{~m}^{3} \times \mathrm{Rp} \quad 350.000=$ Rp 10.332

Semen $=0,005 \mathrm{~m}^{3} \times \mathrm{Rp} 3.465 .000=$ Rp20.439

2. Setelah harga material yang digunakan dalam plesteran dihitung maka selanjutnya dihitung upah pekerja pembuatan plesteran dinding ecobrick yang dihitung sebagai berikut:

$\begin{array}{lllll}\text { Pekerja } & 0,2 & \text { OH } & \text { Rp 131.603 } & =\text { Rp } 26.320 \\ \text { Tukang Batu } & 0,1 & \text { OH } & \text { Rp 164.503 } & =\text { Rp } 16.450 \\ \text { KepalaTukang } & 0,01 & \text { OH } & \text { Rp 197.404 } & =\text { Rp } 1.974 \\ \text { Mandor } & 0,01 & \text { OH } & \text { Rp 230.305 } & =\text { Rp } 2.303\end{array}$

Sehingga biaya yang dikeluarkan dalam pembuatan plesteran ecobrick ialah sebesar Rp 77.810. Maka total biaya pembuatan dinding ecobrick untuk $1 \mathrm{~m}^{2}$ ialah $\mathbf{R p}$ 170.000, oleh karena itu berdasarkan hasil perhitungan pekerjaan secara keseluruhan untuk dinding dan plesteran dalam $1 \mathrm{~m}^{2}$, biaya pembuatan ecobrick lebih murah dibandingkan dengan pembuatan dinding bata merah dengan tebal $1 / 2$ bata, pembuatan ecobrick menghemat biaya sebesar $30 \%$. Hal tersebut dikarenakan botol dan plastik kemasan mudah ditemukan dan lebih murah harganya dibandingkan dengan bata. 


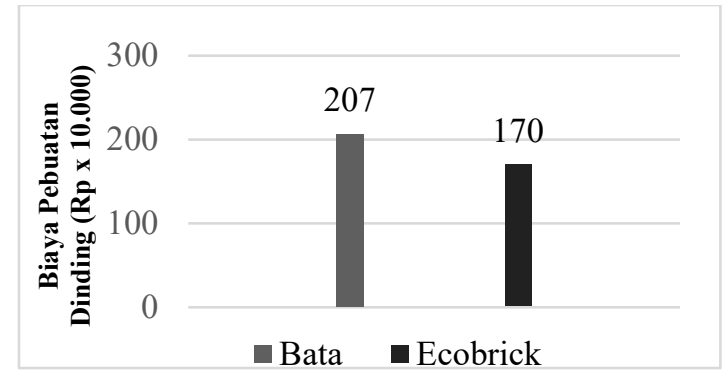

Gambar 6 Perbandingan Biaya Pembuatan Dinding per $1 \mathrm{~m}^{2}$

\section{KESIMPULAN}

1. Berdasarkan analisis kuat tekan dan lentur dinding didapatkan hasil sebagai berikut:

a. Kuat tekan dinding pasangan bata dengan plesteran lebih tinggi dibandingkan dinding ecobrick, dimana kekuatan tekan pasangan bata sebesar 2,38 MPa dan ecobrick sebesar $1,31 \mathrm{MPa}$.

b. Kuat lentur dinding ecobrick lebih tinggi dibandingkan pasangan bata, nilai kekuatan lentur ecobrick sebesar 1,23 $\mathrm{MPa}$ sedangkan dinding bata $1,18 \mathrm{MPa}$.

2. Hasil analisis statistik dengan uji $\mathrm{T}$, kekuatan tekan dinding pasangan antara kedua benda uji memiliki perbedaan yang signifikan sedangkan kekuatan lentur dinding tidak memiliki perbedaan yang signifikan.

3. Biaya pembuatan dinding dari ecobrick untuk $1 \mathrm{~m}^{2}$ ialah sebesar Rp 159.000, sedangkan biaya pembuatan bata dengan tebal $1 / 2$ bata sebesar Rp 207.200, dinding dari ecobrick dapat menghemat biaya sebesar 38\%.

\section{SARAN}

1. Kemasan plastik yang digunakan untuk mengisii botol PET sebaiknya dipotong dengan menggunakan mesin penghancur plastik sehingga didapatkan ukuran yang sama dan dapat memudahkan pekerjaan.

2. Sebaiknya dimensi benda uji yang dibuat disesuaikan dengan dimensi beban merata yang mengenai benda uji.

3. Perlu dilakukan penelitian lebih lanjut dengan mencari substitusi material lainnya di dalam botol PET terutama dari bahan limbah, sehingga dapat mengurangi pencemaran lingkungan.

\section{DAFTAR PUSTAKA}

[BPS] Badan Pusat Statistik. 2013. Proyeksi Penduduk Indonesia 2010-2035. Jakarta (ID): BPS.

Shoubi, M. V., Shoubi, M. V., \& Barough, A. S. (2013). Investigating the application of plastic bottle as a sustainable material in the building construction. International

Journal of Science, Engineering and Technology Research, 2(1), 28-34.

Nursia, \& Harudu, L. (2016). Dampak Penambangan Batu Bata terhadap Degradasi Lingkungan di Kelurahan Kolasa Kecamatan Parigi Kabupaten Muna. Jurnal Penelitian Pendidikan Geografi, 1(4), 115-129.

Supriyadi, S., \& Septinar, H. (2018). Kerusakan Lingkungan Akibat Industri Batu Bata di Desa Pangkalan Benteng Sebagai Sumber Pembelajaran Ilmu Pengetahuan Sosial (Geografi) di Mts Guppi Sukamoro. Jurnal Swarnabhumi: Jurnal Geografi dan Pembelajaran Geografi, 3(2), 136-142.

[BPS] Badan Pusat Statistik. 2018. Statistk Lingkungan Hidup Indonesia 2018. Jakarta (ID): BPS 
JSIL | Lubis dan Erizal. : Ecobrick Sebagai Solusi Dinding Nonstruktural

Pascanawaty, M. S., Sukrawa, M., \& Budiwati, I. M. (2016). Studi Eksperimental Tentang Kekuatan Dinding Bata dengan Perkuatan. Jurnal Spektran, 4(1).

Leksono, R. S., \& Kristijanto, H. (2012).

Studi Pengaruh Kekuatan dan Kekakuan Dinding Bata Pada Bangunan Bertingkat. Jurnal Teknik ITS, 1(1), D30-D33.

[BSN] Badan Standardisasi Nasional. 1996a. Metode pengujian kuat tekan dinding pasangan bata merah di laboratorium. SNI 034164-1996. Jakarta (ID):BSN.

[BSN] Badan Standardisasi Nasional. 1996b.Metode pengujian kuat lentur dinding pasangan bata di laboratorium. SNI 03-4165-1996. Jakarta (ID): BSN.

[BSN] Badan Standardisasi Nasional. 2000. Bata merah pejal untuk pasangan dinding. SNI 15-20942000. Jakarta (ID): BSN.

[BSN] Badan Standardisasi Nasional. 2008a. Tata cara perhitungan harga satuan pekerjaan plesteran untuk konsruksi gedung dan perumahan. SNI 2837- 2008. Jakarta (ID): BSN.

[BSN] Badan Standardisasi Nasional. 2008b. Tata cara perhitungan harga satuan pekerjaan dinding untuk konsruksi gedung dan perumahan. SNI 6897-2008. Jakarta (ID): BSN.

BS EN 772-1. 2011. "Methods of Test for Masonry Units Part 1: Determination of Compressive Strength." BSI Standards Publication.

BS EN 1052-2. 1999. "Methods of Test for Masonry - Part 2: Determination of Flexural Strength. "European Committee for Standardization (CEN)".

[KEPGUB] Keputusan Gubernur Jawa Barat. 2019. Standar Biaya
Khusus Pemerintah Daerah Provinsi Jawa Barat Tahun Anggaran 2019. Bandung (ID): Pemda Jabar. 